\title{
Evaluation of erosive potential of fruit juices in children aged 3-6 years
}

\author{
Aby J Mathew ${ }^{1}$, BM Shanthala ${ }^{2 *}$, Bobby Wilson ${ }^{2}$, Libina Isahak $^{3}$, Priyanka Atul Shah ${ }^{4}$ and Meera Rose Cherian ${ }^{3}$ \\ ${ }^{1}$ Department of Pedodontics, Government Dental College, Kottayam, India \\ ${ }^{2}$ Department of Pedodontics and Preventive Dentistry, Coorg Institute of Dental Sciences, Karnataka, India \\ ${ }^{3}$ Department of Pedodontics, P.M.S. College of Dental Sciences and Research, India \\ ${ }^{4}$ Department of Pedodontics, Pandit Deendayal Upadhyay Dental College and Hospital, India
}

\section{Introduction}

Dental erosion, defined as the progressive, irreversible loss of dental hard tissues by a chemical process without bacterial involvement, is currently considered a significant clinical challenge [1-4]. With the decline of caries in many societies an increasing attention has been focused on tooth wear from erosion, abrasion and attrition.

Epidemiological studies have indicated that dietary factors are more important in the development of dental erosion in children due to the consumption of acidic drinks and foods [1,2,5-8]. Aspects of lifestyle that have been associated with erosion are the consumption of low $\mathrm{pH}$, sugar-containing sports drinks and infant fruit juices, which have $\mathrm{pH}$ ranging from 3.6-4.1. Diets that may pose an erosive risk to the teeth are those that include an unusually high consumption of citrus fruits, fruit juice and carbonated soft drinks. In addition, there has been increasing concern to adopt a healthy diet (including fruits, vegetables and fruit juices) which has led to increased consumption of acidic foods and drinks [3]. In relation to the intake of acidic drinks, several factors may affect the severity of dental erosion such as the frequency and amount of acidic drinks intake, the length of time the drink is retained in the mouth. Consumption of acidic drinks overnight has been shown to significantly increase the prevalence and severity of dental erosion [6].

The role of saliva in dental erosion is not fully understood, probably as a result of the complexity of inter- and intra-individual salivary conditions. Saliva is known to be important for protection against an erosive challenge by dilution and clearance of acidic products [1-4,814]. One important role of saliva is the maintenance and protection of the dental hard tissues by providing a source of calcium and phosphate ions. It could be shown that subjects with erosion have less calcium and inorganic phosphate in saliva. Those individuals with low salivary calcium concentrations have a higher critical $\mathrm{pH}$ ( $\mathrm{pH}$-value at which hydroxyapatite starts to dissolve) and will therefore be more susceptible to demineralization than subjects with higher calcium concentrations.

Few studies published dealing with the salivary factors which may influence dental erosion, found different results concerning a possible relation between salivary flow rate, buffering capacity and $\mathrm{pH}$ value [1$4,8,12-14]$. Study design was planned to evaluate the erosive potential of commercially available fruit juices. Based on this a hypothesis was stated that the $\mathrm{pH}$ and acidity of the commercial available juices affects the salivary parameters when consumed over a period of time.

\section{Materials and methods}

The present study was carried out after obtaining necessary ethical clearance from the Institutional Review Board. An oral health survey was conducted in the Anganwadis of Virajpet taluk. The word Anganwadi means "courtyard shelter" in Indian languages. They were started by the Indian government in 1975 as part of the Integrated Child Development Services program to combat child hunger and malnutrition. A typical Anganwadi centre provides basic health care in Indian villages. It is a part of the Indian public health-care system. The children are provided with midday meals from these Anganwadi centers.

The oral health survey was carried out in the Anganwadis of Virajpet. n=143 and diet their diet practices was recorded. A mean def score of 1.3357 was recorded from the survey with a standard deviation of 2.66153. The survey was carried out by a single examiner. The survey revealed that the children were not getting an adequate supply of fruits in their diet.

50 Children from 5 Anganwadis in the age group of 3-6 yrs with no relevant medical history and def $=0$ were selected and divided into 5 groups using stratified random sampling technique. Informed consent was obtained from the parents of the selected children after explaining the purpose of the study and clarifying their queries regarding the study. Before enrolling the first participant into the study was registered in the Clinical Trial Registry of India. (CTRI/2014/07/004801)

Commercially available packaged fruit juices of Tropicana (brand found in Bradenton, Florida, USA in 1947) was used, for it is enjoyed almost everywhere in the world. Tropicana has matured into one of the most respected beverage brands. In India, Tropicana comes in two categories: 100\% Juices (sold as Tropicana 100\%) and Juice Beverages (sold as Tropicana). The juices that were included in the study were Tropicana 100\% Orange juice, Tropicana 100\% Grape juice, Tropicana 100\% Apple juice and Tropicana Litchi juice which did not contain any added preservatives or added sugars.

${ }^{\star}$ Correspondence to: Shanthala BM, Department of Pedodontics and Preventive Dentistry, Coorg Institute of Dental Sciences, KK Campus, Virajpet, Karnataka, India, E-mail: shanthalapedo@cids.edu

Key words: Erosion, saliva, salivary parameters

Received: June 05, 2018; Accepted: June 25, 2018; Published: June 28, 2018 
The juices were evaluated for the total acidity, type of acid and titrable acidity and classified based on the results obtained as acidic and alkaline juice. The total acidity in Orange juice was $0.74 \mathrm{~g} / 100 \mathrm{ml}$ and the type of acid Citric acid, in the Grape juice the total acidity was 0.32 $\mathrm{g} / 100 \mathrm{ml}$ and the type of acid Tartaric acid, in the Apple juice was 0.31 $\mathrm{g} / 100 \mathrm{ml}$ and the type of acid Maleic acid, in the Litchi juice was $0.32 \mathrm{~g}$ / $100 \mathrm{ml}$ and the type of acid Tartaric acid. The children were given 60 $\mathrm{ml}$ of the fruit juices as assigned to the group (Group 2- Orange Juice, Group 3- Apple Juice, Group 4- Grape Juice, Group 5- Litchi Juice) in the mornings as brunch for a period of 15 days. Whereas the children in the Group 1 was not given any type of juice and served as control group.

The Saliva samples were taken at 4 time points of the study and was analysed for salivary parameters calcium, phosphorus, bicarbonate and $\mathrm{pH}$. This was done at baseline, 7 days, 15 days and 30 days of the study. Saliva sampling was carried out in the morning between 10.30 am and $11.30 \mathrm{am}$. The children were advised not to drink or eat for 2 hours prior to collection. After an initial swallow of saliva, unstimulated saliva was obtained by passive dripping into a sterile saliva collection vial during 5 minutes with the subjects sitting in a relaxed upright position $[2,15]$. The samples were stored at $-20^{\circ} \mathrm{C}$ within 30 minutes of collection and remained there until determination of salivary parameters.

The salivary samples were centrifuged to remove bacteria and other extraneous material. The resulting clarified solutions were used for biochemical assays to measure salivary $\mathrm{pH}$ and the concentrations of total calcium, inorganic phosphatase and bicarbonate.

The results obtained from the salivary analysis were statistically evaluated using ANOVA analysis.

\section{Results}

The variation in salivary Calcium after 7, 15 and 30 days compared to baseline values was found to be more in the Orange juice followed by Apple, Litchi, Grape and control group (Figure 1) and was statistically significant (Table 1).

The variation in salivary calcium was found to be statistically significant between baseline and 7,15 and 30 days.

\section{Phosphorus}

The variation in salivary Phosphorus after 7, 15 and 30 days when compared to baseline it was found to be more in Litchi juice group followed by Grape, Orange, Apple and control (Figure 2) and was statistically significant (Table 1).

The variation in salivary phosphorus was found to be statistically significant between baseline and 7,15 and 3 days.

\section{pH}

The variations in salivary $\mathrm{pH}$ after 7,15 and 30 days when compared to baseline was found to be more in Litchi, and grape followed by orange, apple and control (Figure 3 ) was statistically significant (Table 1).

The variation in salivary $\mathrm{pH}$ was found to be statistically significant between baseline and 7 and 15 days, but it was not significant between baseline and 30 days.

\section{Bicarbonate}

The variations in salivary bicarbonate after 7, 15 and 30 days when compared to baseline was found to be more in Orange juice followed by apple, grape and litchi and control (Figure 4) was not statistically significant (Table 1).

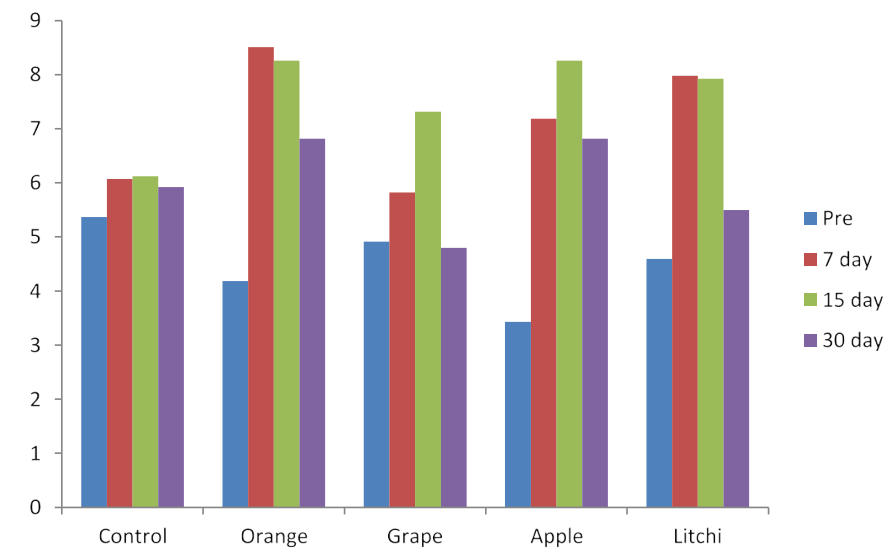

Figure 1. Salivary Calcium levels at baseline, 7 days, 15 days and 30 days

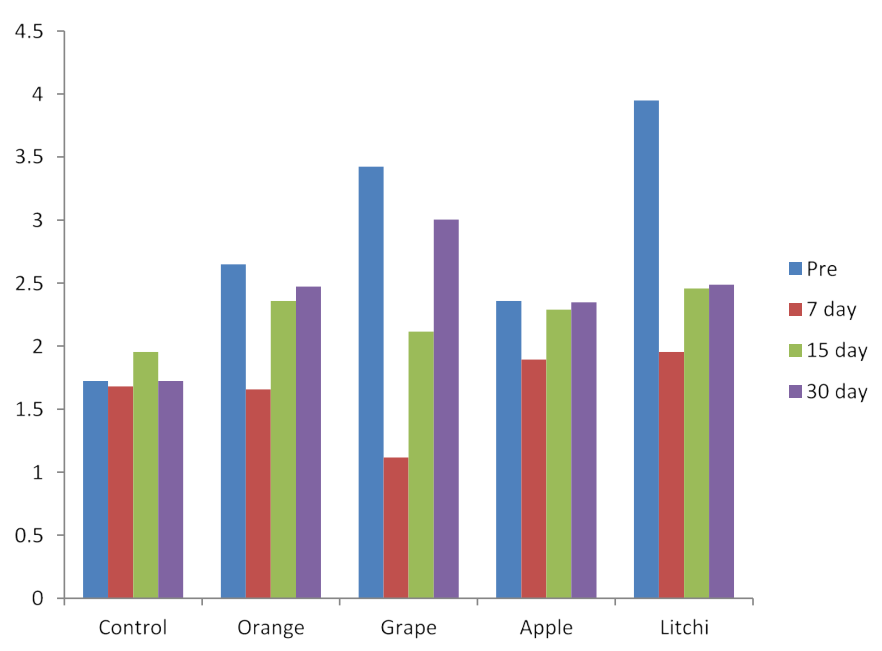

Figure 2. Salivary Phosphorus levels at baseline, 7 days, 15 days and 30 days

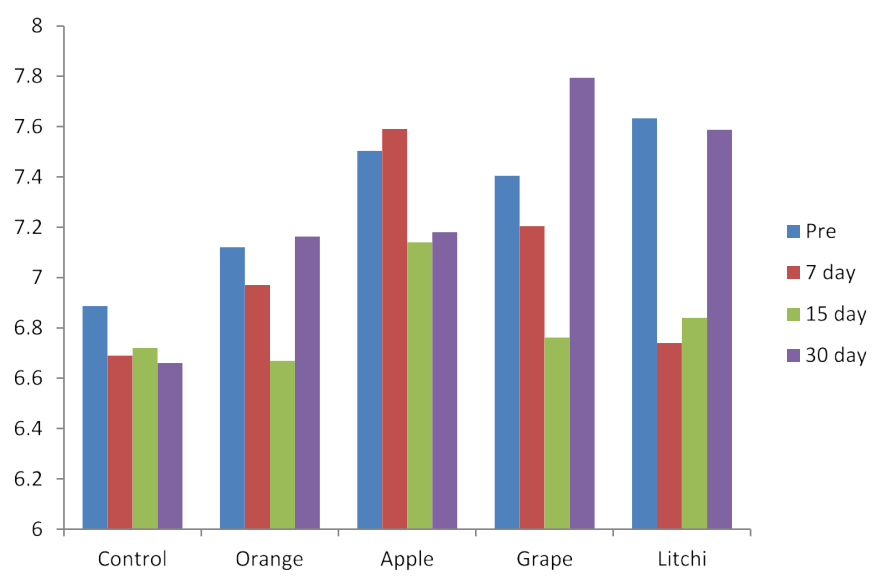

Figure 3. Salivary pH levels at baseline, 7 days, 15 days and 30 days

The variation in salivary bicarbonate was found to be statistically significant between baseline and 7 days, whereas it was found to be non-significant between baseline and 15 and 30 days.

\section{Discussion}

The erosion does not seem to have the increased susceptibility to deciduous enamel in the initial phase, but rather over time and/or 
Table 1. ANOVA Test for the comparison of type of juices and the period of consumption of juices

\begin{tabular}{|c|c|c|c|c|c|c|}
\hline Source of variation & df & sum of squares & mean sum of squares & F-value & p-value & Remarks \\
\hline \multicolumn{7}{|l|}{ Calcium } \\
\hline I & 4 & 43.8800 & 10.9700 & 6.764 & $4.29 \mathrm{e}-05$ & Significant \\
\hline II & 3 & 273.4000 & 91.1300 & 56.1900 & $<2.00 \mathrm{e}-16$ & Significant \\
\hline I * II & 12 & 103.7400 & 8.6400 & 5.3300 & $1.10 \mathrm{e}-07$ & Significant \\
\hline Residuals & 180 & 291.9400 & 1.6200 & & & \\
\hline \multicolumn{7}{|l|}{ Phosphorus } \\
\hline I & 4 & 18.69 & 4.671 & 7.7594 & $1.12 \mathrm{e}-15$ & Significant \\
\hline II & 3 & 34.71 & 11.571 & 18.810 & $1.17 \mathrm{e}-10$ & Significant \\
\hline I * II & 12 & 26.48 & 2.206 & 3.586 & $8.27 \mathrm{e}-05$ & Significant \\
\hline Residuals & 180 & 110.73 & 0.615 & & & \\
\hline \multicolumn{7}{|l|}{ pH } \\
\hline I & 4 & 10.17 & 2.5413 & 10.933 & $5.87 \mathrm{e}-08$ & Significant \\
\hline II & 3 & 7.66 & 2.5546 & 10.990 & $1.16 \mathrm{e}-06$ & Significant \\
\hline I * II & 12 & 8.01 & 0.6676 & 2.872 & 0.0012 & Significant \\
\hline Residuals & 180 & 41.84 & 0.2324 & & & \\
\hline \multicolumn{7}{|l|}{ Bicarbonate } \\
\hline I & 4 & 13.48 & 3.370 & 2.357 & 0.55399 & not significant \\
\hline II & 3 & 28.06 & 9.354 & 6.541 & 0.000319 & Significant \\
\hline $\mathrm{I} * \mathrm{II}$ & 12 & 68.31 & 5.693 & 3.981 & $1.85 \mathrm{e}-05$ & Significant \\
\hline Residuals & 180 & 257.42 & 1.430 & & & \\
\hline
\end{tabular}

Data Dictionary: I - Type of juice; II- Duration of juice consumption

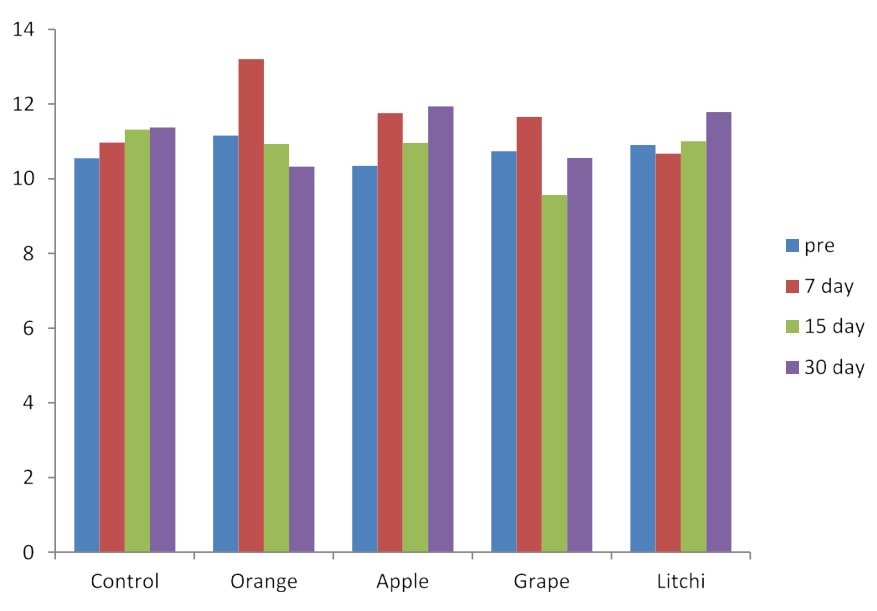

Figure 4. Salivary Bicarbonate levels at baseline, 7 days, 15 days and 30 days

with increasing softening power of the acid. This is of importance to the clinician given the reduced dimension of the deciduous dentition and the continuously increasing intake of soft drinks by children [4]. In addition, softer enamel such as the enamel of deciduous teeth is more prone to abrasion, which may explain the clinical picture often seen in children with significant tooth surface loss. The overlapping of erosion with attrition and/or abrasion is probably more pronounced in deciduous than in permanent teeth $[1,2,4,16]$.

Diet and lifestyle make up a large component of the extrinsic factors involved in dental erosion. Many population studies on children have shown a direct correlation between consumption of carbonated drinks, fruit juices and dental erosion in children, with excessive consumption of acidic drinks and food being reported as the most important extrinsic factor contributing to dental erosion [1,5,6-8]. The recent dramatic increase in consumption of acidic fruit juices, fruit drinks and carbonated beverages is now thought to be the leading cause of dental erosion observed among children and adolescents $[5-7,17]$. The most important erosive component in these drinks is citric acid which is included in these juices for its refreshing taste [5].
The various acid sources from diet can contribute to the chemical erosion to tooth surface $[1-8,10,17,18]$. The results from the present study attribute to the fact that the acidic components of fruit juices (Orange juice, Grape juice, Apple juice and Litchi Juice) had a significantly varying effect on the salivary parameters.

Regular consumption of Orange juice, Apple juice and sweetened instant teas were suggested to be discouraged as they have an erosive effect on the human enamel. The observed increased tooth wear associated with deciduous teeth and the erosive fruit-based drinks tend to be introduced at a very early age, thereby increasing the time to which deciduous teeth are exposed to their damaging effect [16]. This view was further confirmed from this study with all the fruit juices tested were of acidic contents with titrable acidity varying from 0.31 $\mathrm{g} / 10 \mathrm{ml}$ to $0.74 \mathrm{~g} / 100 \mathrm{ml}$. The orange juice was found to have more erosive potential than other fruit juices used in the study owing to its composition of citric acid and with titrable acidity of $0.74 \mathrm{~g} / 100 \mathrm{ml}$.

Erosive capacity of different drinks, juices and foodstuffs was said to be statistically significantly associated with their acidity, $\mathrm{pH}$ values, phosphate and fluoride contents as well as Calcium and bicarbonate $[1,10]$.

Previously, it was thought that the total acid level (titrable acid) of dietary substances was more important than the $\mathrm{pH}$ [18]. However, these hypotheses have now been refuted with research showing that the main chemical parameter likely to significantly correlate with erosion is the initial $\mathrm{pH}$ of the dietary intake. The type of acid used in the beverage may also affect erosive potential as those drinks containing acids with calcium-chelating properties, such as citrate, may cause erosion at higher $\mathrm{pH}$ levels $[8,9,12]$.

It has been known for a long time that acidic food and drinks may soften dental hard tissues. The erosive activity of citric, maleic, phosphoric and other acids as ingredients of beverages and foodstuffs has been demonstrated in many in vitro, in situ and in vivo studies $[8,12]$. Further a series of studies indicate that the erosive potential of an acidic drink is not entirely dependent on its $\mathrm{pH}$ but is also strongly affected by its titrable acid content and by the calcium chelation properties of the food and beverages as they efficiently bind released 
calcium. The greater the buffering capacity of the drink the longer it will take for the saliva to neutralize the acid $[4,8]$.

Few studies have been published dealing with the salivary factors which may influence dental erosion, but found different results concerning a possible relation between salivary flow rate, buffering capacity and $\mathrm{pH}$ value $[1,2,4,13]$. However saliva is composed of a variety of electrolytes, including calcium and phosphate which contribute to the maintenance of tooth integrity. There have been very few studies comparing salivary calcium and phosphate concentrations in children and adults and relating these to susceptibility to erosion. Anderson et al (2001) measured calcium and phosphate concentrations in rested and unstimulated saliva of 6-12-year-old children and noted that the driving force for demineralization and remineralization is governed by salivary $\mathrm{pH}$-value and calcium concentration. Thereby, individuals with lower salivary calcium concentrations exhibit a higher critical $\mathrm{pH}$ for hydroxyapatite dissolution and a lower driving force for remineralization. For subjects showing dental erosion, Jarvinen et al, found less calcium and phosphate in the saliva, possibly related to a reduced production of unstimulated saliva $[2,4,5]$.

Saliva is known to have many properties that can serve as a protective function against dental erosion [1-4,8,12-14]. This includes dilution and clearance of a potentially erosive agent from the mouth; neutralization and buffering of dietary acids; maintenance of a supersaturated state next to the tooth surface due to the presence of calcium and phosphate in saliva; formation of the acquired pellicle by the adsorption of salivary proteins and glycoproteins, which have the ability to protect the enamel surface from demineralization by dietary acids presence of calcium, phosphate and fluoride are necessary for remineralization $[1,2,4,8,12]$.

The individual manner of drinking acidic soft drinks has been said to affect how long the teeth are in contact with the erosive challenge and therefore influence the pattern of destruction caused by them $[1,4,8-11]$. The drinking method strongly affects tooth-surface $\mathrm{pH}$ and thereby the risk for dental erosion.

Severity of dental erosion depends on multiple factors, such as time of exposure to the erosive agents, mineralization of dental hard tissues, soft tissue anatomy and movement, lifestyle and diet and salivary composition $[11,19]$. In the present study the duration of consumption of fruit juice in children otherwise not exposed to the fruit juices were evaluated. The duration considered was two weeks to compare its effect on pre, in between (at 7 days) and 2 weeks after stopping of the consumption of juices. It was observed from the findings of the present study that there was significant variation in the salivary parameters tested during and after consumption of juices.

Statistically significant differences in susceptibility of deciduous and permanent enamel to erosion appear to emerge over time and with increasing frequency of consumption of acidic beverages [9]. Von Fraunhofer and Rogers, in their study of the effects of soft drinks and other beverages on dental enamel, concluded that reduced residence times of beverages in the mouth by salivary clearance or rinsing appear to be beneficial while Johansson et al. from their study expressed that high erosion was associated with a method of drinking whereby the drink was kept in the mouth for a longer period $[9,11]$. Significant differences in the ability of various drinks to adhere to enamel in vivo has been observed, therefore consumption of soft drinks with a lower ability to stick to the enamel surface than saliva was suggested to be preferable, as these drinks were presumably more easily displaced by saliva [9].
As erosion of primary teeth is considered to be a predictor for erosion and general tooth wear of the permanent dentition, precise preventive and therapeutic measures are necessary to avoid this increasing clinical problem.

\section{Conclusion}

1. The Salivary parameters Calcium, Phosphorus and $\mathrm{pH}$ evaluated for erosive potential in fruit juices showed a significant variation whereas the bicarbonate was not significant.

2. The Orange juice group was found to have more erosive potential than the alkaline based fruit juices (litchi, apple and grape)

3. The period of consumption of either acidic or alkaline fruit juices had a significant effect on salivary parameters.

\section{Clinical significance}

It is suggested to check different organic acids used in the manufacturing of fruit juice in comparison with the natural occurrence of these acids in the fruit itself before recommending consumption of the fruit juices. Still it is best to recommend the consumption of fruits in direct form than as juices, for the fact of added sugars and the organic acids used in the manufacturing contributes to more caries risk experience and erosive potential.

\section{References}

1. Taji S, Seow WK (2010) A literature review of dental erosion in children. Aust Dent $J$ 55: 358-367. [Crossref]

2. Wiegand A, Müller J, Werner C, Attin T (2006) Prevalence of erosive tooth wear and associated risk factors in 2-7-year-old German kindergarten children. Oral Dis 12:117124. [Crossref]

3. Dugmore CR, Rock WP (2004) A multifactorial analysis of factors associated with dental erosion. Br Dent J 196: 283-286. [Crossref]

4. Lussi A (2006) Dental Erosion- from diagnosis to therapy. Bern: Karger

5. Järvinen VK, Rytömaa II, Heinonen OP (1991) Risk factors in dental erosion. J Dent Res 70: 942-947. [Crossref]

6. Huew R, Waterhouse PJ, Moynihan PJ, Kometa S, Maguire A (2011) Dental erosion and its association with diet in Libyan schoolchildren. Eur Arch Paediatr Dent 12: 234-240. [Crossref]

7. Committee on Nutrition (2001) American Academy of Pediatrics: The use and misuse of fruit juice in pediatrics. Pediatrics 107: 1210-1213. [Crossref]

8. Zero DT, Lussi A (2005) Erosion--chemical and biological factors of importance to the dental practitioner. Int Dent J 55: 285-290. [Crossref]

9. Bamisea CT, Kolawolb KA, Oloyedec EO (2009) The Determinants and Control of Soft Drinks-Incited Dental Erosion. Rev Clín Pesq Odontol, Curitiba, V. 5, N. 2, P. 141-154, Maio/Ago.

10. de Carvalho Sales-Peres SH, Magalhães AC, de Andrade Moreira Machado MA, Buzalaf MA (2007) Evaluation of the erosive potential of soft drinks. Eur J Dent 1: 10-13. [Crossref]

11. Johansson AK, Lingström P, Imfeld T, Birkhed D (2004) Influence of drinking method on tooth-surface $\mathrm{pH}$ in relation to dental erosion. Eur J Oral Sci 112: 484-489. [Crossref]

12. Almeida E Silva Js, Baratieri Ln, Araujo E, Widmer N (2011) Dental Erosion: Understanding This Pervasive Condition. J Esthet Restor Dent 2: 205-216.

13. Prabhakar AR, Gulati A, Mehta D, Sugandhan S (2009) Diagnostic Applications of Saliva in Dentistry. Int J Clin Pediatr Dent 2: 7-13.

14. Imfeld T (1996) Dental erosion. Definition, classification and links. Eur J Oral Sci 104 151-155. [Crossref]

15. Edgar Wm, O'mullane DM (1996) Salaiva And Ral Health. $2^{\text {nd }}$ Edn. Great Britian Bdj p. 27.

16. Hunter M, West NX, Hughes JA, Newcombe RG, Addy M (2000) Erosion of Deciduous and Permanent Dental Hard Tissue in the Oral Environment. $J$ Dent 28 : 257-263. [Crossref] 
17. Lussi A, Jaeggi T (2008) Erosion--diagnosis and risk factors. Clin Oral Investig 12 Suppl 1: S5-13. [Crossref]
18. Piangprach T, Hengtrakool C, Kukiattrakoon B, Kedjarune-Leggat U (2009) The effect of salivary factors on dental erosion in various age groups and tooth surfaces. $J \mathrm{Am}$ Dent Assoc 140: 1137-1143. [Crossref]

Copyright: (C2018 Mathew AJ. This is an open-access article distributed under the terms of the Creative Commons Attribution License, which permits unrestricted use, distribution, and reproduction in any medium, provided the original author and source are credited. 